\title{
The 210-kD Nuclear Envelope Polypeptide Recognized by Human Autoantibodies in Primary Biliary Cirrhosis Is the Major Glycoprotein of the Nuclear Pore
}

\author{
Jean-Claude Courvalin," Kaïs Lassoued, ${ }^{\ddagger}$ Eckart Bartnik, ${ }^{5}$ Günter Blobel, ${ }^{5}$ and Richard W. Wozniak ${ }^{5}$ \\ ${ }^{*}$ Centre de Génétique Moléculaire, Centre National de la Recherche Scientifique, Gif sur Yvette, France; ${ }^{\ddagger}$ Laboratoire d'Immunochimie \\ et Immunopathologie, Institut National de la Santé et de la Recherche Médicale, U.108, Paris, France; and \\ ${ }^{\S}$ Laboratory of Cell Biology, Howard Hughes Medical Institute, The Rockefeller University, New York 10021
}

\begin{abstract}
We have recently reported a new family of nuclear autoantibodies in a subset of patients with primary biliary cirrhosis. These antibodies bind to a nuclear envelope polypeptide(s) of $\sim 200 \mathrm{kD}$, the exact identity of which was not established. In this study, we show that all of these autoantibodies are directed against a 210-kD integral membrane glycoprotein of the nuclear pore. (J. Clin. Invest. 1990. 86:279-285.) Key words: autoantibodies • glycoprotein 210 - nuclear pore • primary biliary cirrhosis
\end{abstract}

\section{Introduction}

The nuclear envelope separates cytoplasm from the nuclear compartment in eukaryotic cells (for reviews see references 1 and 2). It is composed of a double membrane, pore complexes, and the nuclear lamina. Nuclear pore complexes are large supramolecular structures with a diameter of $\sim 120 \mathrm{~nm}$ and an estimated mass of $\sim 124 \times 10^{6} \mathrm{D}(3)$. They form transcisternal channels across the nuclear envelope in regions where the double membrane fuses and the nuclear lamina is interrupted. Pore complexes appear to mediate both active and passive transport of proteins and nucleic acids into and out of the nucleus (for a review see reference 4). To date only a few pore complex proteins have been identified. Among the best characterized are two distinct glycoproteins with molecular masses of 62 and $210 \mathrm{kD}(5-8)$. The latter, termed gp210, is an integral membrane protein that possesses high mannose-type oligosaccharides. Gp210 is believed to be involved in the formation of nuclear pores and the anchorage of pore complex constituents to the nuclear membrane $(7,8)$.

Antinuclear antibodies are useful diagnostic markers for autoimmune diseases and probes for cell biology. Recently it was shown that a subset of patients with primary biliary cirrhosis $(\mathrm{PBC})^{1}$ have autoantibodies to a nuclear envelope polypeptide(s) of $\sim 200 \mathrm{kD}(9-11)$. However, its identity could not be

Address reprint requests to Jean-Claude Courvalin, Laboratory of Cell Biology, Box 292, Howard Hughes Medical Institute, The Rockefeller University, 1230 York Ave., New York, NY 10021. This is his current address.

Received for publication 6 July 1989 and in revised form 12 March 1990.

1. Abbreviation used in this paper: $\mathrm{PBC}$, primary biliary cirrhosis.

J. Clin. Invest.

(c) The American Society for Clinical Investigation, Inc.

0021-9738/90/07/0279/07 \$2.00

Volume 86, July 1990, 279-285 clearly defined on the basis of these data. In this report, we present data demonstrating that the target antigen of these antibodies is gp210.

\section{Methods}

Patients. The clinical characteristics of the patients of this study have been already presented (10). Briefly, they all suffered from chronic liver disease with cholestasis. PBC diagnosis was ascertained on the following basis: (a) presence of antimitochondrial antibodies of the M2 subtype (8/9); $(b)$ increased IgM serum level (9/9); (c) histology on liver biopsy (7/7). No other autoantibodies were detected, notably antiDNA, anti-ENA (extractable nuclear antigen), antilamins, and antismooth muscle, with the exception of one patient with CREST syndrome who had anticentromere antibodies. Another patient had a sicca syndrome. The control patients were 24 patients admitted in the same period for PBC but who did not have the anti-200-kD antibodies. When compared to these patients, the only distinctive feature of patients who have the anti-200-kD antibodies was a low titre of antimitochondrial antibodies $(1 / 50$ vs. $1 / 500 ; P<0.05)$. In each immunoblotting or immunoprecipitation experiment using patient's sera, a control was performed using a pool of sera from healthy subjects.

Isolation and fractionation of nuclear envelopes. Rat liver nuclei were isolated from 150 to $200 \mathrm{~g}$ Sprague-Dawley rats according to Blobel and Potter (12). All solutions contained $1 \mathrm{mM}$ PMSF and 10 mM $N$-ethylmaleimide (NEM) according to Kaufman et al. (13). All subsequent steps were performed according to Gerace et al. (14) with slight modifications. Nuclear envelopes were obtained by digestion of nuclei with DNAse I and RNAse A followed by a $1 \mathrm{M} \mathrm{NaCl}$ extraction. Chemical extractions of rat liver nuclear envelopes were performed by resuspending pellets in the appropriate extraction solutions. These solutions contained: (a) $20 \mathrm{mM}$ Tris- $\mathrm{HCl}$ (pH 7.4), $1 \mathrm{mM}$ DTT, $1 \mathrm{mM}$ PMSF, 10\% (wt/vol) sucrose, 2\% (wt/vol) Triton X-100, $0.3 \mathrm{M} \mathrm{NaCl}$; (b) $0.1 \mathrm{~N} \mathrm{NaOH}$ and $1 \mathrm{mM}$ DTT; (c) $0.1 \mathrm{M}$ sodium carbonate, $\mathrm{pH}$ 11.5, and $1 \mathrm{mM}$ DTT. Triton X-100/0.3 M NaCl and sodium carbonate samples were incubated for $30 \mathrm{~min}$ before centrifugation, while $\mathrm{NaOH}$ samples were centrifuged immediately after resuspension. Centrifugation was performed at $200,000 \mathrm{~g}$ for $30 \mathrm{~min}$. Nuclear envelopes were directly solubilized in SDS sample buffer while pellets were washed in $90 \%$ ethanol, then resuspended in SDS sample buffer. Supernatants were precipitated with $10 \%$ TCA, the precipitate was washed in $90 \%$ ethanol and then solubilized in SDS sample buffer. All SDS samples were kept at $70^{\circ} \mathrm{C}$ for $15 \mathrm{~min}$ in the presence of $5 \%$ (vol/vol) 2-mercaptoethanol.

SDS-hydroxyapatite chromatography. SDS-hydroxylapatite chromatography was performed according to Berrios et al. (15), with the following modifications. Rat liver nuclear envelopes were washed with $0.5 \mathrm{M} \mathrm{NaCl}$, and a pellet corresponding to $\sim 3 \mathrm{mg}$ of total protein was solubilized in $2 \mathrm{ml}$ of $2 \% \mathrm{SDS}$ (wt/vol), $100 \mathrm{mM} \mathrm{NaP}_{\mathrm{i}}, \mathrm{pH} 6.8$, and 100 mM DTT. The sample was heated at $60^{\circ} \mathrm{C}$ for $20 \mathrm{~min}$, cooled to room temperature, and diluted 10 -fold with $100 \mathrm{mM} \mathrm{NaP}, \mathrm{pH}$ 6.8. This material was loaded on a 3-ml Bio-Gel HTP column preequilibrated with $0.1 \%$ SDS (wt/vol), $100 \mathrm{mM} \mathrm{NaP}_{i}, \mathrm{pH} 6.8$, and $1 \mathrm{mM} \mathrm{DTT}$. The column was washed with three-column volumes of this buffer and 
eluted with a 20-ml linear gradient of $0.1 \mathrm{M}$ to $0.75 \mathrm{M} \mathrm{NaP}_{\mathrm{i}}, \mathrm{pH} 6.8$, containing $0.1 \%$ SDS (wt/vol), $1 \mathrm{mM}$ DTT. 300- $\mu \mathrm{l}$ fractions were collected. Fractions were diluted to $1 \mathrm{ml}$ with water, precipitated with $10 \%$ TCA (wt/vol), and prepared for SDS-PAGE analysis.

Isolation of Gp210. Gp210 was affinity purified using immobilized lentil lectin as previously described (8).

Immunoblotting. SDS-solubilized proteins were subjected to electrophoresis on either $8 \%$ or $6 \%$ polyacrylamide gels according to Laemmli (16). Polypeptides were electrophoretically transferred to nitrocellulose as previously described $(8,10)$. Immobilized proteins were incubated for $6 \mathrm{~h}$ with patient's sera or a mixture of normal human sera or rabbit antibodies to gp210. The latter have previously been described (8). Binding of antibodies was detected with either antihuman IgG coupled to alkaline phosphatase (Promega Biotec, Madison, WI) or with ${ }^{125}$ I-protein A (New England Nuclear, Boston, MA). Alternatively blots were probed with either ${ }^{14} \mathrm{C}$-labeled Con A (Sigma Chemical Co. St Louis, MO) or with Con A coupled to horseradish peroxidase (HRP) (Vector Laboratories, Inc. Burlingame, CA).

Immunoprecipitation. HeLa cells grown in suspension were radioactively labelled for $16 \mathrm{~h}$ with $0.2 \mathrm{mCi} / \mathrm{ml}\left[{ }^{35} \mathrm{~S}\right]$ methionine in methionine-depleted S-MEM, Joklik-modified medium (Gibco Laboratories, Grand Island, NY). Cells were transferred to PHEM buffer (20 mM Pipes, $20 \mathrm{mM}$ Hepes, pH 6.9, $10 \mathrm{mM}$ EGTA, $5 \mathrm{mM} \mathrm{MgCl} 2,10$ mM NEM, and $1 \mathrm{mM}$ PMSF). An equal volume of PHEM buffer containing $1 \%$ Triton $X-100$ and protease inhibitors $(2 \mu \mathrm{g} / \mathrm{ml}$ leupeptin, $2 \mu \mathrm{g} / \mathrm{ml}$ pepstatin, $200 \mu \mathrm{g} / \mathrm{ml}$ aprotinin, and $2 \mu \mathrm{g} / \mathrm{ml}$ antipaïn) was added, then after a 2-min incubation cells were centrifuged for $5 \mathrm{~min}$ at $2,000 \mathrm{~g}$. The crude nuclear pellet was resuspended in DOC buffer $(100$ mM Tris-HCl, pH 8.3, 2 mM EDTA, 0.1\% SDS, 0.5\% NP-40, 0.5\% Na-deoxycholate), dispersed by sonication, then adjusted to $5 \mathrm{mM}$ iodoacetamide and antiproteases as above. After 15 min centrifugation at $10,000 \mathrm{~g}$, aliquots of the supernatant containing $15 \times 10^{6} \mathrm{cpm}$ were incubated overnight with a 1/50 dilution of patient's sera or control pooled human sera. Samples were then added to $30 \mu \mathrm{l}$ (packed bead volume) protein A-Sepharose 4B (Pharmacia Fine Chemicals, Piscat- away, NJ) and incubated with agitation for $2 \mathrm{~h}$ at $4^{\circ} \mathrm{C}$, then washed four times with DOC buffer and once with distilled water. Beads were then boiled for $3 \mathrm{~min}$ in SDS sample buffer, then the extracted proteins were separated by SDS-PAGE and finally revealed by fluorography (17).

Indirect immunofluorescence. Buffalo rat liver cells (BRL 3A; ATCC CRL 1442) were grown on cover slips, washed with PBS, and then in PEM ( $80 \mathrm{mM} \mathrm{K}$ Pipes, $5 \mathrm{mM}$ EGTA, $1 \mathrm{mM} \mathrm{MgCl}$, pH 6.9). After washing, cells were extracted for $1 \mathrm{~min}$ in PEM solution containing $0.5 \%$ Triton $X-100$ and fixed in methanol for $6 \mathrm{~min}$ at $-20^{\circ} \mathrm{C}$. Alternatively, cells were directly fixed in methanol. First antibodies were used at a 1:100 dilution. Binding was detected with affinity-purified goat $F\left(a b^{\prime}\right) 2$ anti-(human IgG gamma chain) antibodies labeled with FITC (Tago Inc., Burlingame, CA) at the same dilution.

\section{Results}

On the basis of immunoblotting and immunoprecipitation experiments, we have previously shown that a subset of patients with PBC produced autoantibodies directed against a nuclear envelope polypeptide(s) of $\sim 200 \mathrm{kD}(9,10)$. However this polypeptide was not clearly identified since SDS-PAGE of isolated rat liver nuclear envelopes revealed several polypeptides in the $200-\mathrm{kD}$ range. From these polypeptides, three have been previously identified $(7,8,15,18,19)$.

To characterize the antigen recognized by these sera, we first fractionated rat liver nuclear envelopes into integral and peripheral membrane proteins by extracting membranes with alkaline solutions $\left(0.1 \mathrm{~N} \mathrm{NaOH}\right.$ or $\left.0.1 \mathrm{M} \mathrm{Na}_{2} \mathrm{CO}_{3}, \mathrm{pH} 11.5\right)$. After extraction, integral and peripheral membrane proteins were separated by centrifugation. As shown in Fig. 1 (lanes 5-8), peripheral membrane proteins such as lamins $\mathrm{A}, \mathrm{B}$, and $\mathrm{C}$ were largely solubilized with $0.1 \mathrm{M} \mathrm{Na}_{2} \mathrm{CO}_{3}(\mathrm{pH} \mathrm{11.5)}$ and
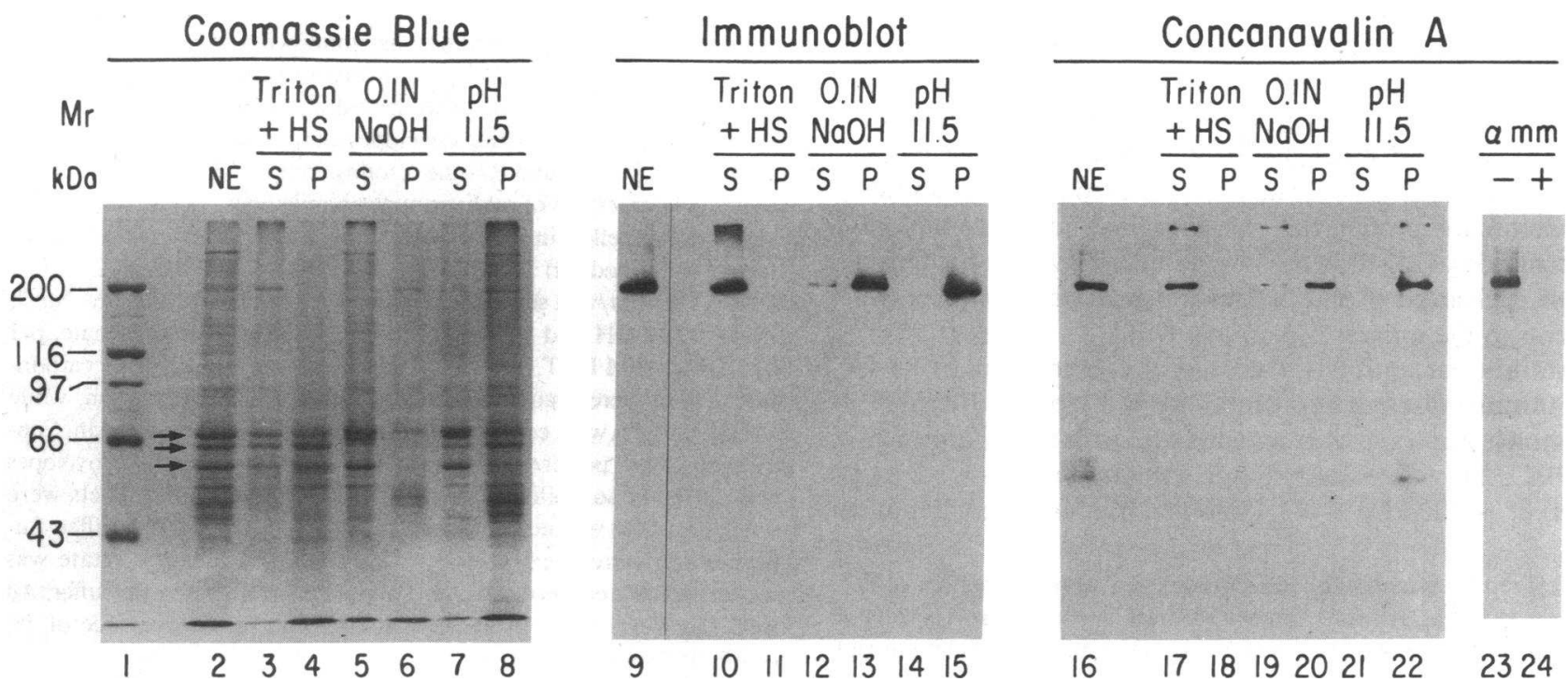

Figure 1. Fractionation behavior of the $\sim 200-\mathrm{kD}$ antigen upon extraction of rat nuclear envelopes with Triton $\mathrm{X}-100 / \mathrm{NaCl}$ or alkaline solutions. Rat liver nuclear envelopes were extracted with either $2 \%$ Triton X-100/0.3 M NaCl, $0.1 \mathrm{~N} \mathrm{NaOH}$, or Na carbonate, pH 11.5 (as indicated in the figure) and centrifuged to yield supernatant $(S)$ and pellet $(P)$ fractions. Polypeptides in these fractions, together with those of unfractionated nuclear envelopes $(N E)$, were separated on polyacrylamide gels and visualized by Coomassie blue staining (lanes 1-8). Identical gels were transferred to nitrocellulose (lanes 9-22) and probed with either the ANA-221 serum (lanes 9-15) or ${ }^{14} \mathrm{C}-\mathrm{Con} \mathrm{A}$ (lanes $16-22$ ). Lanes 23 and 24 correspond to the nuclear envelopes polypeptides probed with Con $\mathrm{A}$ in the absence $(-)$ or in the presence $(+)$ of $0.2 \mathrm{M}$ alpha-methylmannoside $(\alpha-m m)$. Lane 1 corresponds to molecular mass markers (Bio-Rad Laboratories, Cambridge, MA). Arrows on left refer to lamins A $(74 \mathrm{kD}), \mathrm{B}(68 \mathrm{kD})$, and $\mathrm{C}(60 \mathrm{kD})$. The $\sim 200-\mathrm{kD}$ polypeptide recognized by the ANA-221 serum appears entirely in the supernatant of detergent-treated envelopes and in the pellet of alkaline-extracted nuclear envelopes. This fractionation pattern is identical to that displayed by gp2 10 . 
completely extracted with $0.1 \mathrm{M} \mathrm{NaOH}$. Conversely, the majority of gp210 was present in the membrane pellet as judged by Con A binding (Fig. 1, lanes 20 and 22). Solubilization of membrane proteins, including gp210, is achieved by treating nuclear envelopes with $2 \%$ Triton $X-100$ in the presence of 0.3 $\mathrm{M} \mathrm{NaCl}$ (Fig. 1, lanes 17 and 18). The lamins are largely resistant to this extraction procedure and remain in the pellet fraction (Fig. 1, lane 4). Western blotting of nuclear envelope subfractions produced by alkaline or Triton X-100/0.3 M $\mathrm{NaCl}$ extractions performed with a single autoimmune serum (designated ANA-221) reveal that the target antigen fractionates as a membrane protein suggesting it is gp210 (Fig. 1, lanes 10-15).

To further characterize the antigen recognized by this serum, nuclear envelope polypeptides were separated by SDShydroxylapatite chromatography. The eluate of this column contained a major polypeptide of $\sim 200 \mathrm{kD}$ with a peak in the vicinity of fraction 38 (Fig. $2, A$ ). This species was separated from several other polypeptides of a similar molecular mass. The position of this $200-\mathrm{kD}$ polypeptide within the eluate was similar to that previously observed for rat gp210 and for its Drosophila homolog $(15,18)$. Western blot analysis of Fig. 2, (D) shows that the antigen recognized by the ANA-221 serum was an $\sim 200-\mathrm{kD}$ species present in fractions 36 through 50 . This binding pattern was virtually superimposable on that produced by Con A (Fig. 2, B) and an anti-gp210 antiserum (Fig. 2, C).

To complete this identification, gp210 was purified from rat liver nuclei as previously described (8). This procedure allows for purification of gp210 to near homogeneity as judged by SDS-PAGE (Fig. 3, lane 11; see also reference 7) and amino terminal sequence analysis (8). Immunoblot analysis (Fig. $3 \mathrm{D}$, lane 1) shows that ANA-221 reacts with gp210, further demonstrating that it is the target of this particular autoimmune serum.

The ANA-221 serum represents one of several autoimmune sera from patients with PBC that were previously shown to contain antibodies to $\mathrm{a} \sim 200-\mathrm{kD}$ polypeptide of the nuclear envelope (10). To establish that each autoimmune serum was directed against gp210, the nine sera were analyzed using several biochemical procedures.

We first immunoprecipitated total nuclear proteins from $\left[{ }^{35}\right.$ S $]$ methionine-labeled HeLa cells. All sera immunoprecipitated a prominent polypeptide(s) of $\sim 200 \mathrm{kD}$ (Fig. 3, $A$ ). Several sera immunoprecipitated minor components which correspond to other specificities present in these sera. Most of them have a molecular mass of $50-70 \mathrm{kD}$ similar to that of mitochondrial proteins of the M2 complex which are the main autoantibodies associated with primary biliary cirrhosis (20-22). These components likely correspond to mitochondrial contaminants present in the nuclear fraction. Further analysis by Western blotting of total nuclear envelopes revealed a $200-\mathrm{kD}$ polypeptide(s) as the immunoreactive component in this fraction (Fig. 3, B). A higher molecular signal $(\sim 400 \mathrm{kD})$ was occasionally present and may correspond to a SDS-resistant aggregate of the $\sim 200-\mathrm{kD}$ polypeptide(s). Similar high-molecular-mass components were observed by Lozano et al. (11). In a further step of characterization, fraction number 38 of the SDS-hydroxylapatite eluate, which is highly enriched in gp210 (see Fig. $2 A$ ), was used for Western blot analysis. As shown in Fig. $3(C)$, all of the autoimmune sera tested reacted with the $\mathrm{gp} 210$ present in this fraction. This was
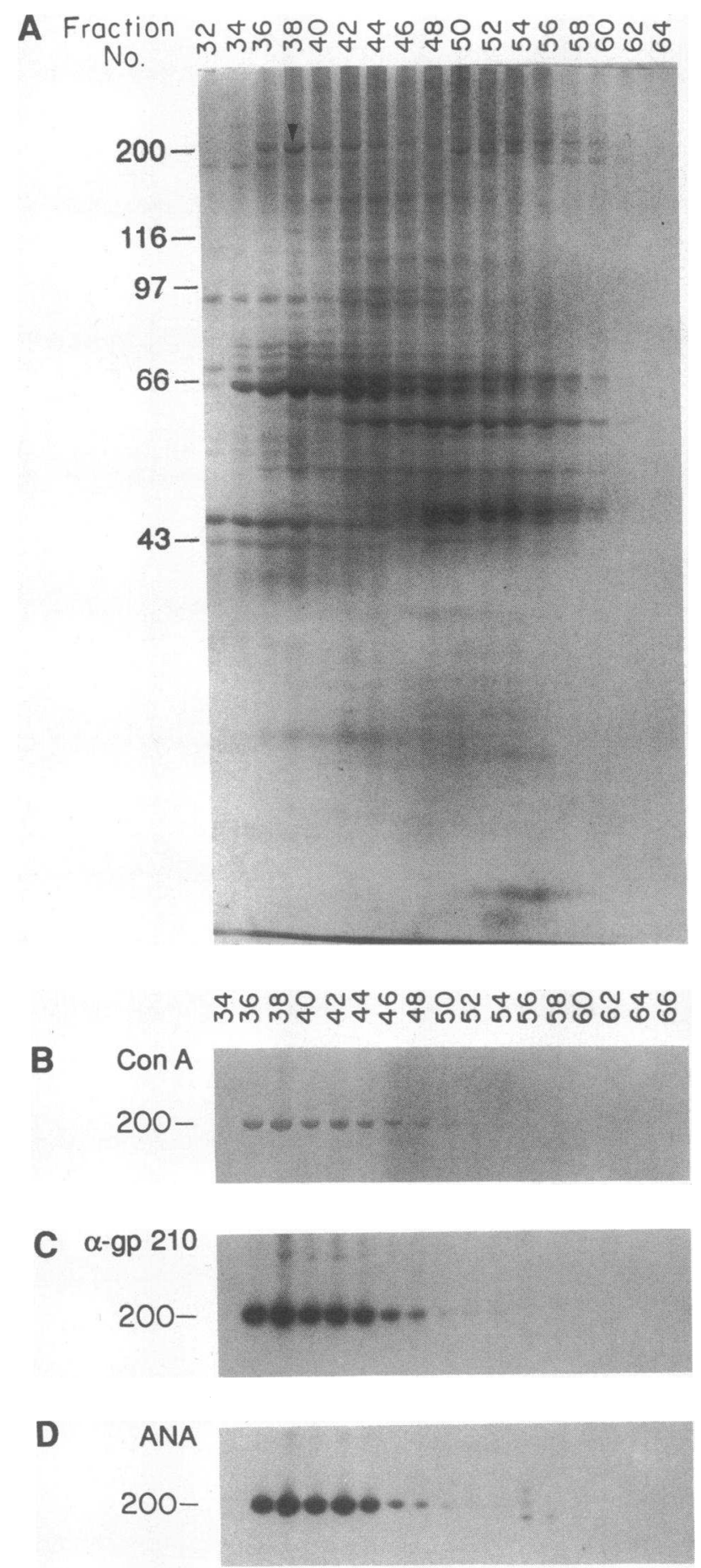

Figure 2. SDS-hydroxylapatite chromatography of salt-washed nuclear envelopes. Polypeptides from salt-washed nuclear envelopes were separated by SDS-hydroxylapatite chromatography. Polypeptides in every other fraction, beginning with fraction 32, were separated on $8 \%$ polyacrylamide gels in SDS and visualized by Coomassie blue staining $(A)$. Most gp210 eluted in fractions 36-44. The position of $\mathrm{gp} 210$ in fraction 38 is indicated by an arrowhead. Three identical sets of samples were separated by SDS-PAGE, transfered to nitrocellulose and probed with either Con A-HRP $(B)$, polyclonal antibodies directed against gp210 (1:250 dilution) $(C)$, or the ANA-221 serum (1:500 dilution) $(D)$. Only the region of interest is shown. The binding pattern produced by ANA-221 serum is identi$\mathrm{cal}$ to that of Con $\mathrm{A}$ and the antibodies directed against $\mathrm{gp} 210$. Molecular mass markers (Bio-Rad) are indicated in kilodaltons. 

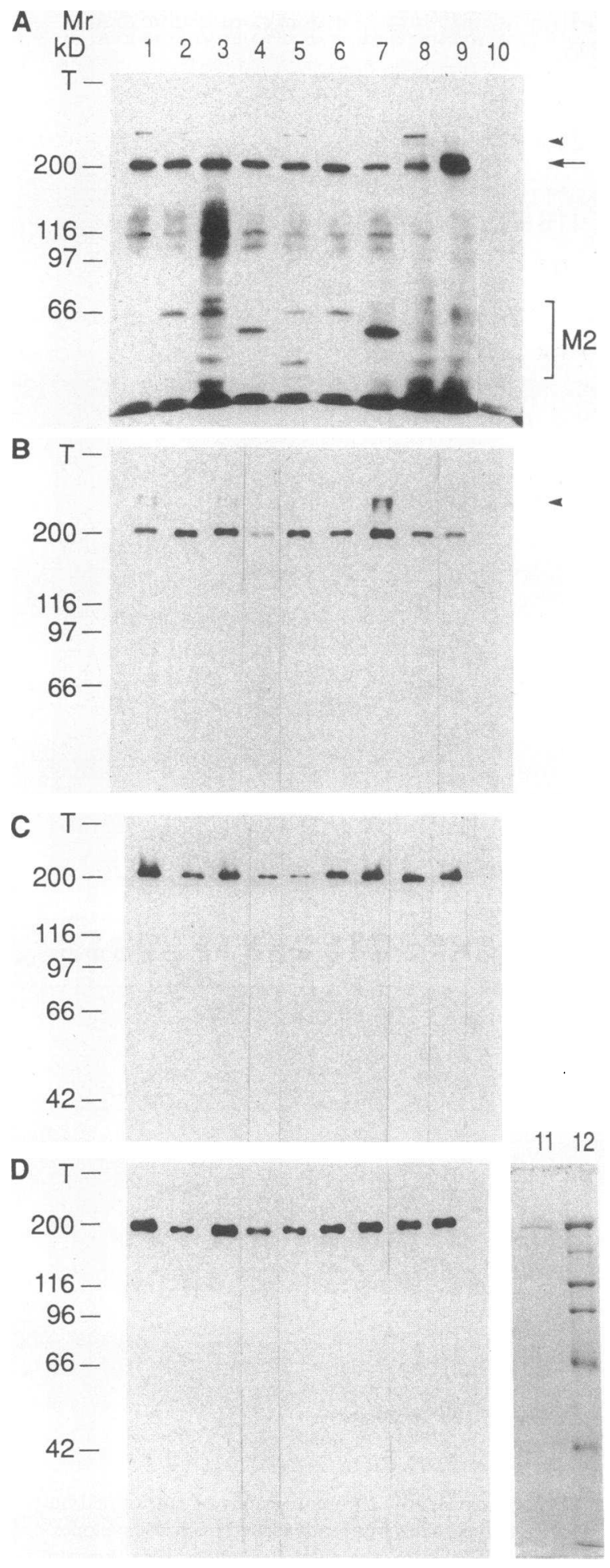

Figure 3. Biochemical and immunological characterization of the $\sim 200$-kD antigen(s) recognized by autoantibodies from nine patients with PBC. (A) Autoradiogram of immunoprecipitated $\left[{ }^{35} S\right] \mathrm{me}-$ thionine-labeled HeLa cell nuclear proteins. $(B, C$, and $D$ ) Immunoblots performed with total rat-liver nuclear envelope proteins $(B)$, polypeptides of fraction 38 of Fig. $2(C)$, and purified gp210 (D). Lanes 1-9 in all four sections show results obtained with sera from nine separate patients. Lane 1 corresponds to ANA-221 serum of Figs. 1 and 2. Lane 10 represents a mixture of normal human sera. Lanes 11 and 12 correspond to Coomassie blue staining of purified confirmed by immunoblotting of purified gp210 (Fig. $3 \mathrm{D}$ ), demonstrating that $\mathrm{gp} 210$ is the target of this group of nine autoimmune sera.

When gp210 was first isolated, it was localized to the pore complex by immunological methods at the ultrastructural level (13). However, in our previous attempts to localize the $\sim 200-\mathrm{kD}$ nuclear antigen, a continuous labeling of the nuclear envelope was observed rather than a punctate staining pattern generally associated with pore complexes (10). To resolve this discrepancy, new immunofluorescent experiments were made using a different cell line and a different fixation procedure. Data in Fig. 4 obtained with ANA-221 show that, under these conditions, the punctated pattern of the nuclear staining was clearly visible, either in Triton-extracted cells (Fig. 4, $c$ and $d$ ) or in nonextracted cells (Fig. 4, $a$ and $b$ ). A similar staining pattern was obtained with the other sera (data not shown). When cells were not Triton extracted before fixation, the mitochondrial staining by autoantibodies to proteins of the M2 complex was preserved.

\section{Discussion}

Extensive research is currently devoted to the identification of the antigens which are the target of antinuclear autoantibodies. Several antigens responsible for homogeneous, speckled, and nucleolar labeling of the nuclei, have been identified (23). Because of their lower frequency, antinuclear antibodies giving a perinuclear labeling have been studied less. We have recently undertaken an analysis of this population of antibodies by collecting from unselected patients, 50 sera giving perinuclear labeling. The most frequent antigens $(11 / 50)$ were lamins $\mathrm{A}, \mathrm{B}$, and $C$, prominent structural proteins of the nuclear envelope (24). The second family of antigens was represented by 10 of these 50 sera recognizing a $\sim 200-\mathrm{kD}$ polypeptide(s) of the nuclear envelope (10). Clinical and biological data were available for nine of the patients. Strikingly, all of these patients suffered from PBC, suggesting that this new specificity could be a marker of the disease. The present study was performed with these nine sera to clearly define the identity of this $\sim$ 200-kD antigen(s).

We show here that all of these nine sera are directed against gp210, a major integral membrane protein of the nuclear pore $(7,8)$. Initial characterization of the antigen recognized by these autoantibodies was performed by immunoprecipitation of HeLa cell nuclear proteins and immunoblotting of rat-liver nuclear envelope fractions enriched in gp210. Further identification was obtained by immunoblotting of purified gp210. Indirect immunofluorescence performed with these sera re-

gp210 and molecular mass markers (Bio-Rad), respectively. 6\% polyacrylamide gels were used in $A$ and $B$ and $8 \%$ gels in $C$ and $D$. Arrowheads point to a $\sim 400-\mathrm{kD}$ component that may represent a SDS-resistant aggregate of gp210. The arrow in $A$ points to a $>200$ $\mathrm{kD}$ additional specificity present in serum 9 . M2 refers to immunoprecipitated proteins in the $50-70 \mathrm{kD}$ range. These molecular masses are similar to that of mitochondrial proteins of the M2 complex which are the prevalent autoantibodies in PBC. These signals likely arose from immunoprecipitation of mitochondrial contaminants which were present in the starting material. On the left of each section molecular mass markers (Bio-Rad) are indicated in kilodaltons. $T$ indicates the top of the resolving gel. 

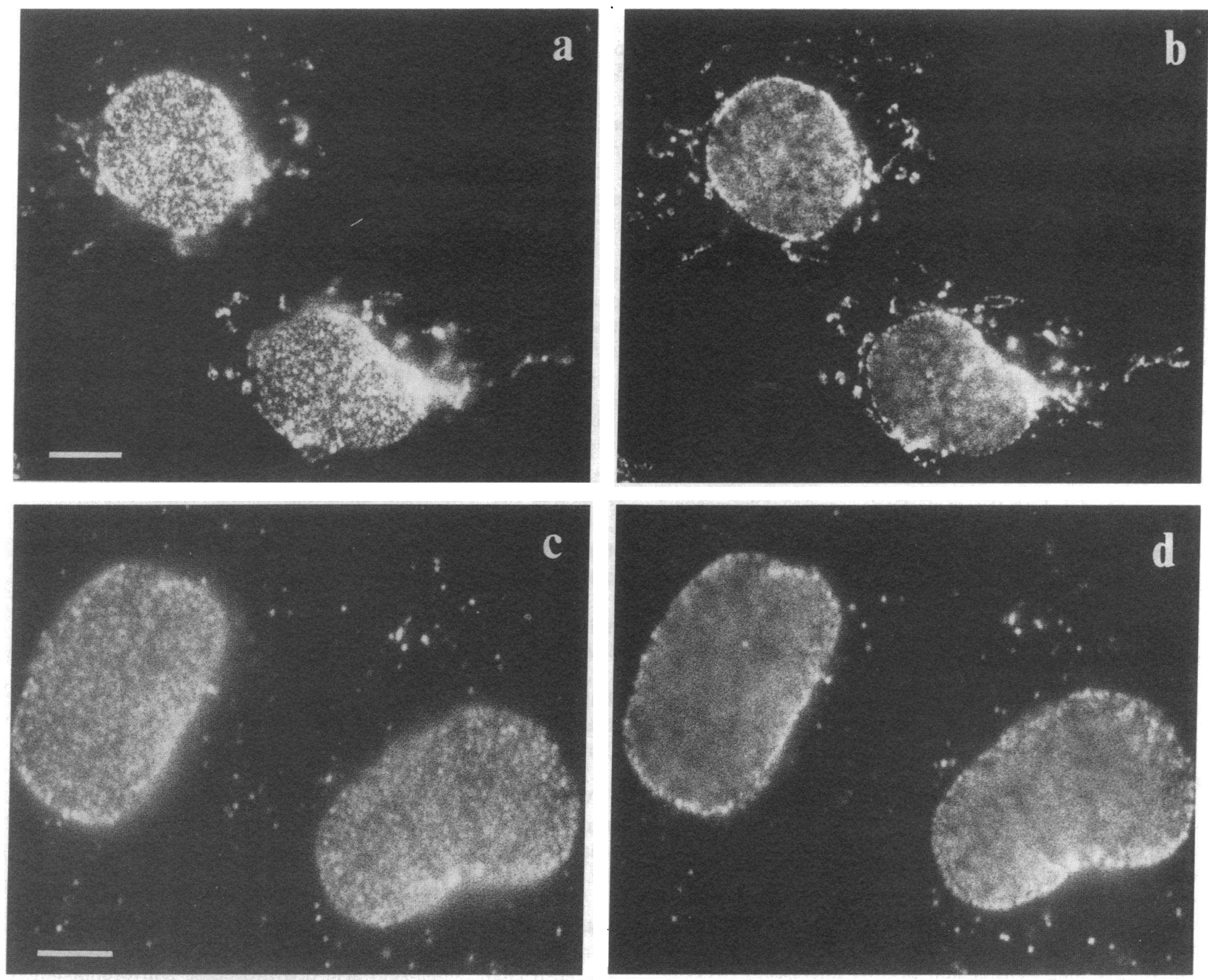

Figure 4. Indirect immunofluorescence of BRL cells performed with ANA-221 serum. BRL cells were fixed and permeabilized in methanol ( $a$ and $b$ ) or extracted with $0.5 \%$ Triton X-100 then fixed in methanol ( $c$ and $d$ ). The images shown in $a$ and $b$ and in $c$ and $d$ represent two separates focal planes within the same field. Together they illustrate a punctate staining pattern and its localization to the periphery of the nucleus. Bars: $(a$ and $b) \sim 2.2 \mu \mathrm{m} ;(c$ and $d) \sim 3.3 \mu \mathrm{m}$.

vealed a peripheral nuclear labeling in a distinct punctate pattern, confirming the nuclear pore localization.

Gp210 is an integral membrane glycoprotein found exclusively in the nuclear envelope. It has been immunolocalized to the junction between the outer and the inner nuclear membranes and represents a major constituent of the nuclear pore. Primary structural information derived from the cDNA-deduced amino acid sequence suggests that the majority of this protein lies within the cisternae of the nuclear envelope with a separate portion extending across the nuclear membrane and into the nuclear pore (8). The relevance of $\mathrm{gp} 210$ in the biogenesis and the function of the nuclear pore complex remains unknown. The concentration of this integral membrane protein at the pore (16-24 copies per pore) would suggest an important role for gp210 in the structural organization of the pore complex as well as its cell cycle-dependent assembly and disassembly.

$\mathrm{PBC}$ is a chronic liver disease of unknown etiology, characterized by progressive inflammatory destruction of the intrahepatic bile ducts (25). Diagnosis usually requires biological and pathological criteria (25-27). Among these criteria, the presence of antimitochondrial (M2) antibodies is highly sug gestive of PBC (28). Major antigens corresponding to the M2 specificity have already been identified as core enzymes of mitochondrial multienzyme complexes $(21,22)$. These antibodies are present in high titer and with a high frequency (90-95\%). However they are not specific as evident by their presence in a broad spectrum of autoimmune diseases (29-31).

Other nuclear specificities were previously found in PBC (32-38). Antibodies to histones are also present with a high frequency in PBC (74\%), but are also found in association with other autoimmune diseases $(23,38)$. Concurrently with the characterization of the $\sim 200-\mathrm{kD}$ antigen as gp210, we performed an extensive study of 150 patients with PBC (39). We showed that, in contrast to other autoantibodies in $\mathrm{PBC}$, antibodies to gp210 are not prevalent in PBC (27\%), but are highly specific since they were not found in association with other autoimmune disease. We also showed that there are a few significant differences in the clinical, immunological, biological, and histological features of the patients with and without antibodies to this protein. However, the group of patients with 
antibodies to gp210 showed a statistically significantly lower titer of antimitochondrial antibodies. A recent report described a new autoantibody from a patient with polymyositis recognizing two proteins of the pore complex, one of which is $200 \mathrm{kD}(40)$. However the relationship to the antigen described in this paper remains to be determined.

The role of autoantigens in the etiology and pathogenesis of various autoimmune diseases has not yet been clarified. Epitope(s) recognized by immunoglobulins in a few autoimmune diseases have recently been identified $(41,42)$. Recombinant DNA technology combined with the $T$ cell cloning approach has allowed the identification of immunogenic epitopes in myasthenia gravis (43). As the cloning of the gp210 has been recently completed (8), this approach will now be possible for this protein.

\section{Acknowledgments}

We thank Drs. C. André, J. C. Brouet, F. Danon, and D. Dhumeaux for the gift of sera. We thank Drs. J. Beisson, F. Gosti, M. N. Guilly, G. Kerryer, C. Klotz, and B. Maro for helpful discussion. We thank Drs. $\mathrm{H}$. Worman and W. Reeves for critical reading of the manuscript. We thank Mrs. M. Bargis-Touchard for secretarial assistance. Cet article est dédié à Thomas.

This research was supported by grant ARC No. 6334, a fellowship from the National Cancer Institute to Dr. J.-C. Courvalin and a fellowship from the Fonds d'Études Médicales de l'Assistance Publique to Dr. K. Lassoued.

\section{References}

1. Newport, J. W., and D. J. Forbes. 1987. The nucleus: structure, function, and dynamics. Annu. Rev. Biochem. 56:335-365.

2. Gerace, L., and B. Burke. 1988. Functional organization of the nuclear envelope. Annu. Rev. Cell Biol. 4:335-374.

3. Reichelt, R., A. Holzenburg, A. Engel, and U. Aebi. 1989. Mass determination of the nuclear pore complex and its sub-complexes by high-resolution scanning transmission electron microscopy (STEM). In Proceedings of the 47th Annual Meeting of the Electron Microscopy Society of America. G. W. Bailey, editor. San Francisco Press, San Francisco, CA. 814-815.

4. Dingwall, C., and R. A. Laskey. 1986. Protein import into the cell nucleus. Annu. Rev. Cell Biol. 2:367-390.

5. Davis, L. I., and G. Blobel. 1986. Identification and characterization of a nuclear pore complex protein. Cell. 45:699-709.

6. Davis, L. I., and G. Blobel. 1987. Nuclear pore complex contains a family of glycoproteins that includes p62: glycosylation through a previously unidentified cellular pathway. Proc. Natl. Acad. Sci. USA. 84:7552-7556.

7. Gerace, L., Y. Ottaviano, and C. Kondor-Koch. 1982. Identification of a major polypeptide of the nuclear pore complex. J. Cell Biol. 95:826-837.

8. Wozniak, R. W., E. Bartnik, and G. Blobel. 1989. Primary structure analysis of an integral membrane glycoprotein of the nuclear pore. J. Cell Biol. 108:2083-2092.

9. Lassoued, K., F. Danon, C. André, M. N. Guilly, J. C. Brouet, D. Dhumeaux, and J. C. Courvalin. 1987. Antibodies directed to $200 \mathrm{kD}$ polypeptide(s) of the nuclear envelope: a new serological marker associated with primary biliary cirrhosis. Hepatology. 7:1115. (Abstr. 372)

10. Lassoued, K., M. N. Guilly, C. André, M. Paintrand, D. Dhumeaux, F. Danon, J. C. Brouet, and J. C. Courvalin. 1988. Autoantibodies to $200 \mathrm{kD}$ polypeptide(s) of the nuclear envelope: a new serologic marker of primary biliary cirrhosis. Clin. Exp. Immunol. 74:283-288.

11. Lozano, F., A. Parès, L. Borche, M. Plana, T. Gallart, J. Rodès, and J. Vives. 1988. Autoantibodies against nuclear envelope-associated proteins in primary biliary cirrhosis. Hepatology. 8:930-938.
12. Blobel, G., and V. R. Potter. 1966. Nuclei from rat liver: isolation method that combines purity with high yield. Science (Wash. DC). 154:1662-1665.

13. Kaufmann, S. H., W. Gibson, and J. H. Shaper. 1983. Characterization of the major polypeptides of the rat liver nuclear envelope. $J$. Biol. Chem. 258:2710-2719.

14. Gerace, L., C. Comeau, and M. Benson. 1984. Organization and modulation of nuclear lamina structure. J. Cell Sci. 1(Suppl.):137-160.

15. Berrios, M., A. J. Filson, G. Blobel, and P. A. Fisher. 1983. A 174 kilodalton ATPase/dATPase polypeptide and a glycoprotein of apparently identical molecular weight are common but distinct components of Drosophila as well as rat liver nuclear structural protein subfractions. J. Biol. Chem. 258:13384-13390.

16. Laemmli, U. K. 1970. Cleavage of structural proteins during the assembly of the head of bacteriophage T4. Nature (Lond.). 227:680-685.

17. Bonner, W. M., and R. A. Laskey. 1974. A film detection method for Tritium-labelled proteins and nucleic acids in polyacrylamide gels. Eur. J. Biochem. 46:83-88.

18. Berrios, M., G. Blobel, and P. A. Fisher. 1983. Characterization of an ATPase/dATPase activity associated with the Drosophila nuclear matrix-pore complex-lamina fraction. J. Biol. Chem. 258:4548-4555.

19. Snow, C. M., A. Senior, and L. Gerace. 1987. Monoclonal antibodies identify a group of nuclear pore complex glycoproteins. $J$. Cell Biol. 104:1143-1156.

20. Ishii, H., K. Saifuku, and T. Namihisa. 1987. Reactivities and clinical relevance of antimitochondrial antibodies to four mitochondrial inner membrane proteins in sera of patients with Primary Biliary Cirrhosis. Hepatology. 7:134-136.

21. Coppel, R. L., L. J. Mc Neilage, C. D. Surh, J. Van de Water, T. W. Spithill, S. Whittingham, and M. E. Gershwin. 1988. Primary structure of the human M2 mitochondrial autoantigen of primary biliary cirrhosis: dihydrolipoamide acetyltransferase. Proc. Natl. Acad. Sci. USA. 85:7317-7321.

22. Surh, C. D., D. J. Danner, A. Ahmed, R. L. Coppel, I. R. Mackay, E. R. Dickson, and M. E. Gershwin. 1989. Reactivity of primary biliary cirrhosis sera with a human fetal liver cDNA clone of branched chain alpha-keto acid dehydrogenase Dihydrolipoamide acetyltransferase, the $52 \mathrm{kD}$ mitochondrial antigen. Hepatology. 9:63-68.

23. Tan, E. M. 1989. Antinuclear antibodies: diagnostic markers for autoimmune diseases and probes for cell biology. Adv. Immunol. 44:93-151.

24. Lassoued, K., M. N. Guilly, F. Danon, C. André, D. Dhumeaux, J. P. Clauvel, J. C. Brouet, M. Seligmann, and J. C. Courvalin. 1988. Antinuclear autoantibodies specific for lamins: characterization and clinical significance. Ann. Intern. Med. 108:829-833.

25. Kaplan, M. M. 1987. Primary biliary cirrhosis. N. Engl. J. Med. 316:521-528.

26. Sherlock, S., and P. J. Scheuer. 1973. The presentation and diagnosis of 100 patients with primary biliary cirrhosis. $N$. Engl. $J$. Med. 289:674-678.

27. Christensen, E., J. Crowe, D. Doniach, H. Popper, L. Ranek, J. Rodes, N. Tygstrup, and R. Williams. 1980. Clinical pattern and course of disease in primary biliary cirrhosis based on an analysis of 236 patients. Gastroenterology. 78:236-246.

28. Lindenborn-Fotinos, J., H. Baum, and P. A. Berg. 1985. Mitochondrial antibodies and their relation to primary biliary cirrhosis: species and nonspecies specific determinants of $\mathrm{M} 2$ antigens. Hepatology. 5:763-769.

29. Mouritsen, S., E. Demant, H. Permin, and A. Wilk. 1986. High prevalence of anti-mitochondria antibodies among patients with some well-defined connective tissue diseases. Clin. Exp. Immunol. 60:68-76.

30. Munoz, L. E., H. G. Thomas, P. J. Scheur, D. Doniach, and S. Sherlock. 1981. Is mitochondrial antibody diagnostic of primary biliary cirrhosis? Gut. 22:136-140. 
31. Berg, P. A., and R. Klein. 1987. Immunology of primary biliary cirrhosis. Baill. Clin. Gastroenterol. 1:675-706.

32. Bernstein, R. M., M. E. Callender, J. M. Neuberger, G. R. V. Hughes, and R. Williams. 1982. Anticentromeres in primary biliary cirrhosis. Ann. Rheum. Dis. 41:612-614.

33. Makinen, D., M. Fritzler, P. Davis, and S. Sherlock. 1983. Anticentromere antibodies in primary biliary cirrhosis. Arthritis Rheum. 26:914-917.

34. Kurki, P., M. Gripenberg, A. M. Teppo, and M. Salaspuro. 1984. Profiles of antinuclear antibodies in chronic active hepatitis, primary biliary cirrhosis and alcoholic liver diseases. Liver. 4:134-138.

35. Powell, F., A. L. Schroeter, and E. R. Dickson. 1984. Antinuclear antibodies in primary biliary cirrhosis. Lancet. i:288-289.

36. Bernstein, R. M., J. M. Neuberger, C. C. Bunn, M. E. Callender, G. R. V. Hughes, and R. Williams. 1984. Diversity of autoantibodies in primary biliary cirrhosis and chronic active hepatitis. Clin. Exp. Immunol. 55:553-560.

37. Ruffati, A., P. Arslan, A. Floreani, G. de Silvestro, A. Calligaro, R. Naccarato, and S. Todesco. 1985 . Nuclear membrane-staining antinuclear antibody in patients with primary biliary cirrhosis. J. Clin. Immunol. 5:357-361.

38. Penner, E., S. Muller, D. Zimmerman, and M. H. V. Van
Regenmortel. 1987. High prevalence of antibodies to histones among patients with primary biliary cirrhosis. Clin. Exp. Immunol. 70:47-52.

39. Lassoued, K., R. Brenard, F. Degos, J-C. Courvalin, C. André, F. Danon, J-C. Brouet, Y. Zine-el-Abidine, C. Degott, S. Zafrani, D. Dhumeaux, and J-P. Benhamou. 1990. Antinuclear antibodies directed to a $200 \mathrm{kD}$ polypeptide of the nuclear envelope in primary biliary cirrhosis. A clinical and immunological study of a series of 150 patients with primary biliary cirrhosis. Gastroenterology. In press.

40. Dagenais, A., V. Bibor-Hardy, and J-L. Senecal. 1988. A novel autoantibody causing a peripheral fluorescent antinuclear antibody pattern is specific for nuclear pore complexes. Arthritis Rheum. 31:1322-1327.

41. Chambers, J. C., and J. D. Keene. 1985. Isolation and analysis of cDNA clones expressing human lupus La antigen. Proc. Natl. Acad. Sci. USA. 82:2115-2119.

42. Lieu, T. S., M. M. Newkirk, J. D. Capra, and R. D. Sontheimer. 1988. Molecular characterization of human Ro/SS-A antigen. J. Clin. Invest. 82:96-101.

43. Melms, A., S. Chrestel, B. C. G. Schalke, H. Wekerle, A. Mauron, M. Ballivet, and T. Barkas. 1989. Autoimmune T lymphocytes in myasthenia gravis. J. Clin. Invest. 83:785-790. 